\title{
Risk Based Analysis for Evaluating of Inspection Scope at PLTGU Muara Karang
}

\author{
Dadang Rohmansyah ${ }^{1}$, Suwarno ${ }^{1}$
}

\begin{abstract}
Power plant operation and plant aging influence plant reliability, strategy, and cost maintenance of PLTGU Block 1 Muara Karang. Several approach has been done to increase maintenance effectiveness as well as reducing it cost. Nevertheless, other strategies are necessary to be further developed adopting best practices in industries. In this study, we used Risk Based Inspection (RBI) method to evaluate scope of inspection on equipment in the HRSG 1.1 Muara Karang. Equipment has been investigated are pressure vessel, heat exchanger tube, and piping. The number of equipment under investigated are 26, where 10 equipments included in the medium risk category and 16 equipments included in the low risk category. There are 2 equipments where the inspection time interval is $\leq 2$ years i.e. high pressure superheater $1 \& 2$.
\end{abstract}

Keywords-Power Plant Operation, Cost Reduction, Risk Based Inspection, Risk Analysis.

\section{INTRODUCTION}

The Muara Karang Block 1 power plant is located in North Jakarta. The power plant is a combined cycle power plant consists of 3 gas turbines, 3 heat recovery steam generators (HRSG) and 1 steam turbine. This unit has been producing for 23 years, and now the power plant operation is as a peaker unit (production during peak load condition). With the current operating conditions, it is possible to reduce the risk of material quality and equipment life. Especially in materials or equipment affected by temperature or pressure differences. It could be seen from the condition of the equipment at the time of inspection, e.g. crack on LP drum separator, and leaks in some tubes in HRSG. With these findings, it is potential to affect the total cost and duration of inspection.

Under these conditions, we need a method to evaluate and ensure maintenance of the existing strategy is appropriate or necessary to add as well as pointed the scope of inspection. In the present study, we used Risk Based Inspection (RBI) method to evaluate the scope of inspection on equipment in the HRSG 1.1 Muara Karang. The author[1] discusses the use of RBI methodology for evaluating maintenance strategies in industrial processes. Among the opportunities and impacts of the occurrence of a failure each was investigated with a risk analysis. All equipment in unit is evaluated and categorized into 5 risk zones based on the RBI results. The author[2] designs a maintenance strategy based on the use of Risk Based Maintenance (RBM) method. Using this methodology, we

\footnotetext{
${ }^{1}$ Dadang Rohmansyah and Suwarno are with Department of Mechanical Engineering, Institut Teknologi Sepuluh Nopember, Surabaya, 60111, Indonesia. E-mail: d_rohmansyah@yahoo.com; warnoise@gmail.com.
}

can estimate the cause of the risk of an unexpected failure as a function of probability of failure (PoF) or the impact of failure $(\mathrm{CoF})$. Maintenance for this equipment is prioritized based on the level of risk of the equipment, so the maintenance strategy is based on reducing overall risk value of an equipment.

\section{METHOD}

The calculation of risk in the Risk-Based Inspection (RBI) methodology involves the determination of a probability of failure combined with the consequence of failure. Failure in American Petroleum Institute 581 is defined as a loss of containment from the pressure boundary resulting in leakage to the atmosphere or rupture of a pressurized component. As damage accumulates in a pressurized component during in-service operation the risk increases. At some point, a risk tolerance or risk target is exceeded and an inspection is recommended of sufficient effectiveness to better quantify the damage state of the component. The inspection action itself does not reduce the risk; however, it does reduce uncertainty thereby allowing better quantification of the damage present in the component[3].

The API RBI methodology may be used to manage the overall risk of a plant by focusing inspection efforts on the process equipment with the highest risk. API RBI provides the basis for managing risk by making an informed decision on inspection frequency, level of detail, and types of NDE. In most plants, a large percent of the total unit risk will be concentrated in a relatively small percent of the equipment items. These potential high risk components may require greater attention, perhaps through a revised inspection plan.

As per definition in[3], risk in defined as following equation (1):

$$
\text { Risk }=\text { PoF } x \mathrm{CoF}
$$

\section{A. Probability of Failure (POF)}

The probability of failure used in API RBI is computed from Equation (2).

$$
P_{f}(t)=g f f \cdot D_{f}(t) \cdot F_{M S}
$$

The probability of failure $P_{f}(t)$, is determined as the product of a generic failure frequency, $g f f$, a damage factor, $D_{f}(t)$, and a management systems factor, $F_{M S}$.

1) Generic failure frequency ( $g f f)$

The general failure frequency of a component is estimated using records from all factories within a company or from various factories within an industry, from literature sources, and general commercial reliability data. Frequency of 
failure is generally intended to be a representative frequency of failure of the quality degradation experienced during operation in a specific environment, and shown for some hole sizes on the types of equipment.

2) Damage factor $\left(D_{f}(t)\right)$

Damage factor is a factor based on the damage mechanism that occurs. There are several examples of damage mechanisms such as thinning, stress corrosion cracking, high temperature hydrogen attack, and mechanical fatigue. Not all of these damage factors are used in calculations when analyzing the probability of a device failure. API 581 provides screening criteria for application of these damage factors. In addition, the damage factor is also determined as a function of the effectiveness of inspection. In this research the damage mechanism is combined with flow accelerated corrosion (FAC). Mechanism of damage caused by FAC (flow accelerated corrosion) occurs when carbon steel components are degraded due to the presence of flowing water or water vapor with oxygen content dissolved therein. When water or water vapor flows in a carbon steel material, the oxide layer on the surface (usually Fe3O4) dissolves into a flowing stream thinning the pipe wall over time. In combined cycle plants, FAC has been the leading cause of HRSG tube failures (HTF) over the last 10 years and represents about 35-40 \% of all HTFs. Both single- and two-phase FAC can occur in low pressure (LP) evaporator and economizer tubing but again there are no decent statistics which separate the two. Two-phase FAC has also been a problem in LP evaporator drum steam separation equipment[4].

3) Management system factor $\left(F_{M S}\right)$

Management System factors ( $F_{M S}$ ) calculates the effect of management system facilities on equipment integrity systems in an industry. This factor consider the probability of failure is accumulation of damage that results a reduction strength will be known based on time and directly proportional to the quality of equipment integrity facility program. This factor is derived from an evaluation between an existing management system facility or an operating unit that affects factory or industry risks.

\section{B. Consequence of Failure (COF)}

The analysis of consequences or impact of occurrence of failure on API 581 is expressed in two categories, which affect the area and on finance. The consequences for the area can be seen in equation 3 as follows.

$$
C A=a \cdot x^{b}
$$

Where variables a and $b$ in equation 3 are fluid references that are released or exposed and can be seen in[5] table 5.2. While $X$ itself is the rate of release or exposure if the release is steady state and continuous, or $\mathrm{X}$ is the mass or amount of fluid released or exposed if the fluid being released or exposed is considered instantaneously. The consequences on costs can be seen in equation 4 .

$$
F C=F C_{c m d}+F C_{\text {prod }}+F C_{\text {inj }}+F C_{\text {affa }}+F C_{\text {envi }}
$$

Where the consequences of costs are affected by the consequences of replacement or repair of components, $F C_{c m d}$, cost of loss of production, $F C_{\text {prod }}$, cost of accidents, $F C_{i n j}$, cost of damage to equipment or components around it, $F C_{a f f a}$, and cost of environmental pollution, $F C_{\text {environ. }}$. In this study the consequences that affect are cost of loss of production or occur derating, cost of accidents, cost of damage to equipment or components around it and cost of damage to equipment or components. The cost of influence on the environment is not quantified because the fluids in HRSG do not include flammable and toxic fluids.

After the probability of failure and the consequences of failure are known, put into equation 1 to search risk categories for each equipment. After that, display it in the risk matrix, and make inspection schedules and scope of inspection work to mitigate these risks.

\section{Case Study}

As described above, in this study the equipment investigated in the RBI application is pressure vessel and heat exchanger tube equipment in HRSG 1.1 Muara Karang. The RBI concept refers to the API 581 standard, where the frequency of common failures and procedures determining the damage factor of each damage mechanisms is provided. Mechanism of damage done in this research is thinning, SCC Amine Cracking, CUI, HTHA, and FAC. Screening mechanism for damage mechanism can be seen in[3] page 5.2, 8.3, 17.3, and 20.3. The table 1 shown of screening criteria for Flow Accelerated Corrosion (FAC).

The value of generic failure frequency for High Pressure Low Pressure Drum equipment, heat exchanger tubes, and steam line can be seen in[3] table 4.1. HRSG equipment specifications that will be inspected can be seen in Table 2 as follows.

\section{RESUlT AND DISCUSSION}

Based on data above then put in the calculation based on the procedures that have been provided in American Petroleum Institute (API) 581. Table 3 shown some of result selected the highest and lowest risk category.

Table 1 Probability of Failure, Damage Factor, Consequence of Failure and Risk Ranking for each HRSG Equipment selected the highest and lowes risk category

From the table above for heat exchanger tube equipment no calculation of the consequences of failure, this is because according to the reference/procedure of API 581, where for heat exchanger tube the consequence of failure calculated is only based on cost consequences. From the results of these calculations it is known there are 10 equipment that are included in the medium risk and 16 equipment that include into low risk.

Based on the RBI concept, follow up for equipment included in the low risk category is only monitored. For equipment included in the medium risk category more focused follow-up is conducted, i.e. by determining the next inspection schedule. According to API 581 the 
inspection scheduling for pressure vessel, heat exchanger tube, and piping is based on the results of the risk obtained, but the interval itself is not given a definite calculation, since API 581 submits the inspection scheduling to the appliance owner according to the risk limit accepted by the owner. The author[6] determines the inspection schedule based on the level of risk and also the mechanism of damage that occurs in the tool and described in equation 5 as follows.

$$
N I D=I_{e f} \times C \times R_{L}
$$

In the equation next inspection schedule, NID, is determined as a product of the effectiveness of the inspection, $\mathrm{I}_{\mathrm{ef}}$, Confidence rating, $\mathrm{C}$, and service life, RL. The value of inspection effectiveness is $0-1$, the value is based on the category of the effectiveness of inspection. While the value of confidence rating is taken based on the risk level of less than 0.5 for a high risk level and more than 0.5 for a low risk level.

From the results of calculations for 10 equipment that are included in the medium risk category, there are 2 equipment where the next inspection schedule is $\leq 2$ years and 8 other equipment $\geq 10$ years. After being known the next inspection schedule of each equipment next step in risk mitigation efforts is to determine the scope of job inspection in this case is an assessment. In API 581 inspection effectiveness is very influential to the value of damage factor, so the risk mitigation to decrease the risk level is with the inspection schedule and level or category of inspection. For 10 equipment included in the medium risk category the scope of job inspection carried out is the UT thickness, radiography, and in situ metallography at $\geq$ $50 \%$ of the surface area of the equipment.

\section{CONCLUSION}

From the results of this study the concept of RBI can be applied to pressure vessel equipment, heat exchanger tube and piping on HRSG. The RBI concept can be used as a comparison in determining maintenance policies. When the RBI implementation is done properly, the RBI concept helps in improving security and reduces inspection and maintenance costs on power plant units.

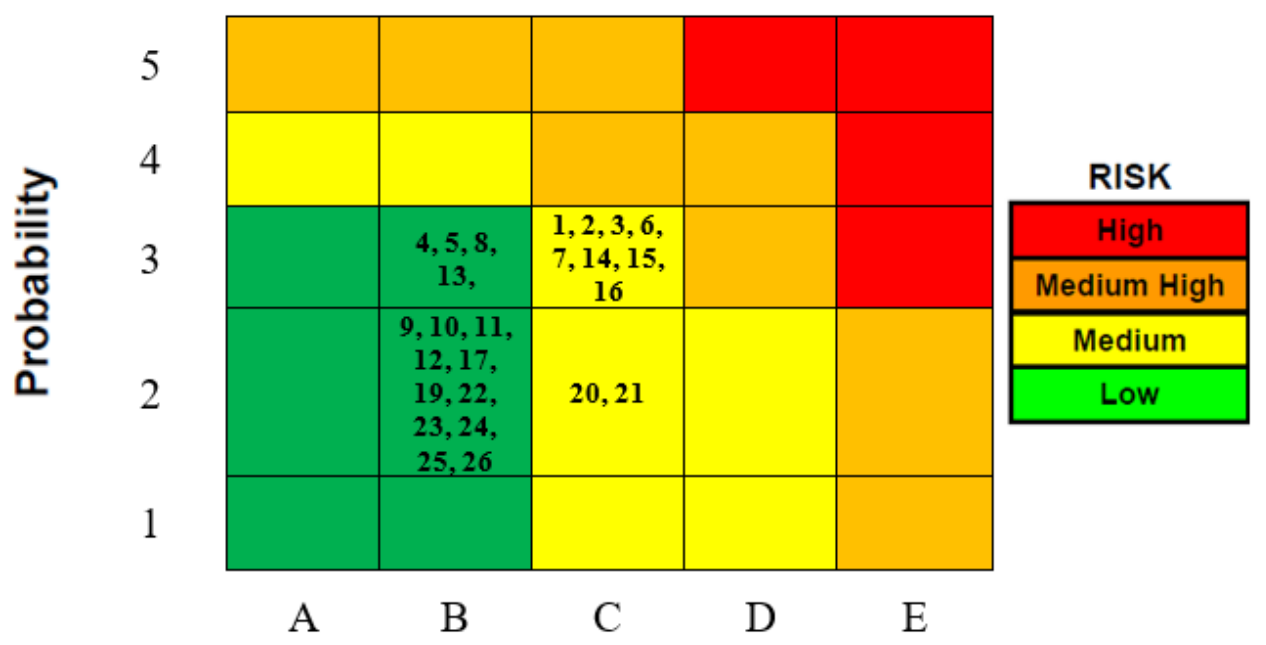

\section{Consequence}

Figure 1. Risk Matrix HRSG Equipment.

TABLE 1.

SCREENING CRITERIA FOR FLOW ACCELERATED CORROSION (FAC)

\begin{tabular}{cl}
\hline \hline Damage Factor & Screening Criteria \\
\hline FAC & $\begin{array}{l}\text { If the component's material of construction is carbon or low alloy steel and the process environment contains } \\
\text { oxygen at } \mathrm{pH}>7.5 \text { in any concentration, then the component should be evaluated for susceptibility to FAC }\end{array}$ \\
\hline \hline
\end{tabular}

TABLE 2.

SPECIFICATIONS OF HRSG EQUIPMENT

\begin{tabular}{clcccccc}
\hline \hline No & \multicolumn{1}{c}{ Equipment } & OD (In) & Thickness (mm) & T Operasi (C) & P Operasi (psi) & Flow Rate (lbs) & Material \\
\hline 1 & LP Economizer & 1.25197 & 3.2 & 43.26 & 376.127 & 415483 & ST35.8/I \\
2 & LP Eco Inlet Header & 6.62598 & 6.3 & 46.18 & 387.004 & 415483 & ST35.8/I \\
3 & LP Eco Outlet Header & 6.62598 & 6.3 & 153.35 & 403.06 & 415483 & ST35.8/I \\
4 & LP Drum & 94.4882 & 18 & 161.9 & 94.129 & 390866 & ST 41KT
\end{tabular}


The $4^{\text {th }}$ International Seminar on Science and Technology

August $9^{\text {th }}$ 2018, Postgraduate Program Institut Teknologi Sepuluh Nopember, Surabaya, Indonesia

\begin{tabular}{|c|c|c|c|c|c|c|c|}
\hline 5 & Deaerator & 86.6142 & 12 & 42.3 & 307.48 & 390866 & ST $41 \mathrm{KT}$ \\
\hline 6 & LP Inlet header evaporator & 6.62598 & 10 & 187.96 & 174.045 & 28020 & ST35.8/I \\
\hline 7 & LP Outlet Header Evap & 6.62598 & 12.5 & 187.96 & 174.045 & 28020 & ST35.8/I \\
\hline 8 & LP Evap Tubes & 1.25197 & 2.6 & 187.96 & 174.045 & 28020 & ST35.8/I \\
\hline 9 & LP SH Tubes & 1.49606 & 2.6 & 319.74 & 96.493 & 91249 & ST35.8/I \\
\hline 10 & LP Inlet header SH & 10.748 & 10 & 319.74 & 96.493 & 91249 & ST35.8/I \\
\hline 11 & LP outlet header SH & 14 & 12.5 & 319.74 & 96.493 & 91249 & ST35.8/I \\
\hline 12 & LP Steam Line & 14 & 8 & 319.74 & 96.493 & 91249 & ST35.8/I \\
\hline 13 & HP Eco Tubes & 1.25197 & 3.2 & 286.97 & 1031.655 & 102603 & ST35.8/III \\
\hline 14 & HP Eco Inlet Header & 6.62598 & 16 & 286.97 & 1031.655 & 102603 & ST35.8/III \\
\hline 15 & HP Eco Outlet Header & 6.62598 & 16 & 286.97 & 1031.655 & 102603 & ST35.8/III \\
\hline 16 & HP Drum & 82.6772 & 60 & 292.2 & 1114.617 & 104565 & 15NiCuMoNb5 \\
\hline 17 & HP Eva Tubes & 1.25197 & 3.2 & 292.4 & 1117.706 & 109305 & ST35.8/III \\
\hline 18 & HP Eva Inlet Header & 14 & 30 & 292.4 & 1117.706 & 10930 & $15 \mathrm{Mo3}$ \\
\hline 19 & HP Eva Outlet Header & 14 & 30 & 292.4 & 1117.706 & 109305 & $15 \mathrm{Mo} 4$ \\
\hline 20 & HP SH 1 Tubes & 1.25197 & 3.2 & 468.56 & 1089.757 & 195285 & 13 Cr Mo 44 \\
\hline 21 & HP SH 2 Tubes & 1.25197 & 4 & 480.76 & 1057.181 & 253752 & 10 Cr Mo 910 \\
\hline 22 & HP SH 1 Inlet Header & 10.748 & 25 & 458.32 & 1107.22 & 163957 & $15 \mathrm{Mo3}$ \\
\hline 23 & HP SH 1 Outlet Header & 12.752 & 30 & 474.43 & 1064.288 & 240987 & 10 Cr Mo 910 \\
\hline 24 & HP SH 2 Inlet Header & 12.752 & 32 & 480.76 & 1057.181 & 253752 & 13 Cr Mo 44 \\
\hline 25 & HP SH 2 Outlet Header & 14 & 32 & 523.57 & 1035.861 & 292024 & X 10 Cr Mo VNb91 \\
\hline 26 & HP Steam Line & 10.748 & 28 & 523.57 & 1035.861 & 292024 & 10 Cr Mo 910 \\
\hline
\end{tabular}

TABLE 3.

Probability of FAILURE, DAMAgE FACTOR, CONSEQUENCE OF FAILURE AND RISK RANKING FOR EACH HRSG EQUIPMENT SELECTED THE HIGHEST AND LOWES RISK CATEGORY

\begin{tabular}{lccccccc}
\hline \multicolumn{1}{c}{ Equipment } & DF Total & Pof & CA final (ft2) & FC final (\$) & Prob Category (range) & CA (ft2) & FC (\$) \\
\hline LP Economizer Tube & 20.379 & 0.0006 & - & 190023.1 & 3 & - & C \\
LP Inlet header evaporator & 20.379 & 0.0006 & 1924 & 129087.9 & 3 & $\mathrm{C}$ & $\mathrm{C}$ \\
LP Inlet header SH & 6.5948 & 0.0002 & 444 & 75859.87 & 2 & $\mathrm{~B}$ & $\mathrm{~B}$ \\
HP Drum & 21.379 & 0.0007 & 782 & 206150.4 & 3 & $\mathrm{~B}$ & $\mathrm{C}$ \\
HP SH 1 Tubes & 8.5948 & 0.0035 & - & 138217.8 & 2 & - & $\mathrm{C}$ \\
HP SH 2 Tubes & 15.595 & 0.0035 & - & 138217.8 & 2 & - & $\mathrm{C}$ \\
\hline \hline
\end{tabular}

\section{REFERENCES}

[1] Z. Tan, J. Li, Z. Wu, J. Zheng, and W. He, "An evaluation of maintenance strategy using risk based inspection,” Saf. Sci., vol. 49, no. 6, pp. 852-860, Jul. 2011.

[2] F. G. Carazas and G. F. M. Souza, "Risk-based decision making method for maintenance policy selection of thermal power plant equipment,” Energy, vol. 35, no. 2, pp. 964-975, Feb. 2010.

[3] American Petroleum Institute (API), Risk-based inspection technology, 2nd ed. Washington D.C.: American Petroleum Institute, 2008.
[4] R. B. Dooley, "Flow accelerated corrosion in fossil and combined cycle/HRSG plants," Power Plant Chem., vol. 10, no. 2, pp. 68-91, 2008.

[5] L. Krishnasamy, F. Khan, and M. Haddara, "Development of a risk-based maintenance (RBM) strategy for a power-generating plant," J. Loss Prev. Process Ind., vol. 18, no. 2, pp. 69-81, Mar. 2005.

[6] M. Al Qathafi and S. Sulistijono, "Studi aplikasi metode Risk Based Inspection (RBI) semi-kuantitatif API 581 pada production separator,” J. Tek. ITS, vol. 4, no. 1, pp. F89-F94, Mar. 2015. 